\title{
Erratum to: Fluoro-deoxy-glucose positron emission tomography for evaluation of indeterminate lung nodules: assigning a probability of malignancy may be preferable to binary readings
}

Suk Chul Kim • Josef Machac • Borys R. Krynyckyi • Karin Knesaurek • Daniel Krellenstein · Barbara Schultz • Allen Gribetz • Louis DePalo • Alvin Teirstein · Chun K. Kim

Published online: 17 March 2010

(C) The Japanese Society of Nuclear Medicine 2010

Erratum to: Ann Nucl Med (2008) 22:165-170

DOI 10.1007/s12149-007-0112-1

The name of the first author should be given as Suk Chul Kim, not Suk C. Kim, as originally published.

The online version of the original article can be found under doi:10.1007/s12149-007-0112-1.

S. C. Kim · J. Machac · B. R. Krynyckyi - K. Knesaurek

C. K. Kim

Department of Radiology, Mount Sinai School of Medicine,

The Mount Sinai Hospital, New York, NY, USA

D. Krellenstein

Department of Surgery, Mount Sinai School of Medicine,

The Mount Sinai Hospital, New York, NY, USA

B. Schultz · A. Gribetz $\cdot$ L. DePalo · A. Teirstein

Department of Medicine, Mount Sinai School of Medicine,

The Mount Sinai Hospital, New York, NY, USA

C. K. Kim $(\bowtie)$

Division of Nuclear Medicine, Department of Radiology,

University of Maryland Medical System, 22 S. Greene St.,

Baltimore, MD 21201, USA

e-mail: ckim@umm.edu 